
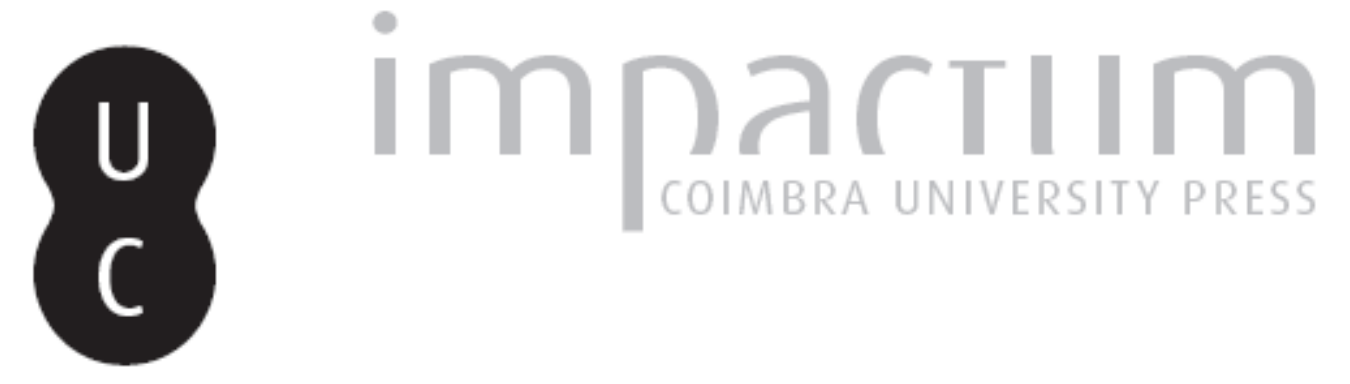

\title{
As mesas comestíveis da Eneida: alguns aspectos da culinária romana
}

\section{Autor(es): $\quad$ Dias, Paula Barata}
Publicado por: Associação Portuguesa de Estudos Clássicos; Instituto de Estudos Clássicos

URL persistente:

URI:http://hdl.handle.net/10316.2/30468

DOI:

DOI:http://dx.doi.org/10.14195/0872-2110_49_5

Accessed : $\quad$ 26-Apr-2023 12:52:36

A navegação consulta e descarregamento dos títulos inseridos nas Bibliotecas Digitais UC Digitalis, UC Pombalina e UC Impactum, pressupõem a aceitação plena e sem reservas dos Termos e Condições de Uso destas Bibliotecas Digitais, disponíveis em https://digitalis.uc.pt/pt-pt/termos.

Conforme exposto nos referidos Termos e Condições de Uso, o descarregamento de títulos de acesso restrito requer uma licença válida de autorização devendo o utilizador aceder ao(s) documento(s) a partir de um endereço de IP da instituição detentora da supramencionada licença.

Ao utilizador é apenas permitido o descarregamento para uso pessoal, pelo que o emprego do(s) título(s) descarregado(s) para outro fim, designadamente comercial, carece de autorização do respetivo autor ou editor da obra.

Na medida em que todas as obras da UC Digitalis se encontram protegidas pelo Código do Direito de Autor e Direitos Conexos e demais legislação aplicável, toda a cópia, parcial ou total, deste documento, nos casos em que é legalmente admitida, deverá conter ou fazer-se acompanhar por este aviso.

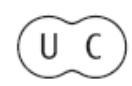




\section{Boletim de}

\section{Estudos Clássicos}

Associação Portuguesa de Estudos Clássicos Instituto de Estudos Clássicos

Coimbra

Junho de 2008 


\section{AS MESAS COMESTÍVEIS DA ENEIDA Alguns ASPECTOS da Culinária RoMana}

Num passo muito conhecido da Eneida, no canto III (vv. 253-257), as Harpias prevêem para Eneias e seus companheiros um aziago futuro, de errância e de fome: - "Só atingireis a Itália quando comerdes as próprias mesas".

Italiam cursu petitis ventisque uocatis:

Ibitis Italiam portusque intrare licebit

Sed non ante datam cingetis moenibus urbem

Quam uos dira fames nostraeque iniuria caedis

Ambesas subigat malis absumere mensas ${ }^{1}$.

"buscais o caminho para a Itália e convocais os ventos:

A Itália chegareis, e ser-vos-á permitido entrar nos seus portos

Mas não cingireis com muralhas a cidade prometida

Sem que antes uma fome terrível e as ofensas pelo crime contra nós

Vos forcem a devorar as mesas, a rodeá-las com os maxilares."

Anquises procura neutralizar o mau presságio, que parece anunciar um futuro irrealizável, com uma prece aos Deuses "Di, prohibete minas" (v. 265) e imediatamente retomam a viagem. De facto, que circunstâncias extremas geradas pela fome poderiam justificar a ingestão das próprias mesas?

Já no canto VII (vv. 107-121), a armada troiana aporta na embocadura do Tibre e, já em terra, improvisam uma singela refeição. Recorrem aos frutos que colhem das árvores e colocam-nos sobre bases cozidas de cereais. A fome é tanta que, comidos os frutos, os companheiros de Eneias comem também estes cereais. Iulo faz essa observação, com espanto e pesar, fornecendo a chave interpretativa a Eneias, que decifra o enigma. Chegaram, de facto, a Itália, pois estão a comer as próprias mesas.

${ }^{1}$ Virgile, Oeuvres, Paris, Classiques Hachette, s.d., p. 362. As traduções são da nossa responsabilidade. 
Aeneas primique duces et pulcher Iulus corpora sub ramis deponunt arboris altae, instituuntque dapes et adorea liba per herbam subiciunt epulis (sic Iuppiter ipse monebat) et Cereale solum pomis agrestibus augent. consumptis hic forte aliis, ut vertere morsus exiguam in Cererem penuria adegit edendi, et violare manu malisque audacibus orbem Fatalis crusti, patulis nec parcere quadris: "Heus, etiam mensas consumimus!" inquit Iulus; Nec plura alludens. Ea uox audita laborum Prima tulit finem, primamque loquentis ab ore Eripuit pater ac stupefactus numine pressit. Continuo: "Salue, fatis mihi debita tellus, Vosque ait, o fidi Troiae, saluete, Penates"

"Eneias, os chefes mais importantes e o formoso Iulo Estendem-se sob os ramos de uma grande árvore; Preparam a refeição, e dispõem sobre os bolos de trigo, $\mathrm{Na}$ erva, as iguarias - assim era por ordem de Júpiter E juntam ao trigo simples frutos silvestres.

Após terem comido isto e o resto, como a falta do que comer Os forçou a virar os dentes em direcção à modesta oferta de Ceres, A quebrar com as mãos e com maxilares audaciosos A borda do pão reclamado pelos fados, sem poupar os bocados partidos: "Eh lá, até as mesas devoramos" diz sem mais Iulo, a gracejar. Ouvidas estas palavras, logo fica claro o fim das suas provações, E o pai toma-a da boca que primeiro a disse, e guarda-a, tomado de espanto pelo oráculo Imediatamente exclama: - Salve ó terra que me é devida pelos fados E Vós, leais penates de Tróia, saúdo-vos..."

A profecia das Harpias afinal não anunciava um destino impossível, desde que os Troianos percorressem não só o duro caminho físico através dos mares, mas também o não menos duro percurso que conduz os homens da ignorância quanto ao seu destino e do desespero até ao conhecimento e à esperança.

Destacamos, das palavras de Celeno, a referência simbólica à fundação de uma cidade, que se realiza pela circunscrição de um espaço através da construção de muralhas. Na verdade, a Harpia acaba por descrever um 
processo que se sabe estar na génese da aventura da sedentarização humana, que se tornou estável e progressivamente complexa à medida que foi avançando o domínio das técnicas agrícolas. Assim, à fundação de uma cidade fica simbolicamente associada a descoberta da transformação dos cereais, ou seja, do pão.

Virgílio acaba assim de incluir no seu magistral poema e dar forma literária a um facto nuclear da aventura humana a caminho da vida em cidades, marcada pelo pão, pela transformação dos produtos agrícolas, como elemento essencial.

Da importância do pão na vida romana quotidiana dá notícia a célebre expressão da sátira X de Juvenal "panem et circenses", afinal a que se reduziam os anseios das multidões que viviam em Roma, no séc. I d.C.: alimentos e diversões básicas e gratuitas. Esta era a metonímia que exprimia o "encher da barriga e do olho", desafogo que o primeiro século imperial estava disposto a oferecer aos habitantes de Roma.

A mais nobre das modalidades romanas de casamento, a confarreatio, era assim designada por incluir uma cerimónia presidida pelo flamen dialis ou pelo pontifex maximus, em que os noivos comiam um far ou um panis fareus feito de farinha de espelta (far, farris, termo latino de que deriva farina e o português "farinha") grosseiramente moída.

O prestígio da cerimónia e a simplicidade do pão obtido desta forma pode indicar a ancestralidade deste ritual na vida dos romanos, que associa o acto simbólico de partilhar o pão ao início da vida de um casal e de uma nova casa. O pão surge assim, mais uma vez mas numa dimensão mais restrita, ou nuclear, associado a um acto fundacional (não de uma cidade, mas de uma das suas células), e a uma dimensão religiosa.

A arqueologia das cidades romanas revelou o fabrico e o comércio do pão como actividades intensivas, quer pela descoberta de padarias, de locais de venda e de frescos que representam o comércio do pão. Pompeios e o Museu Arqueológico de Nápoles ilustram bem esta realidade ${ }^{2}$.

2 Graffitti de Pompeios destacam precisamente a importância que o fornecimento de pão e os profissionais da panificação teriam nas cidades romanas: (CIL IV 329 Iulium Polybium aedilem oro vos faciatis. Panem bonum fert, "Votem em Júlio Políbio para Edil. Ele traz bom pão"; CIL IV 886 Civilium Polybium duumuir oro uos faciatis multum pistores rogant "Políbio para duûmviro, é o que vos pedem encarecidamente que escolham, entre muitos cidadãos, os padeiros". 
A observação permite-nos deduzir que o pão usado pelos romanos era muito semelhante ao nosso: redondo, fermentado, cozido em forno, cómodo ao transporte e ao armazenamento. Quanto ao tipo de cereais, seriam usados trigo de variedades meridionais e primitivas, como o trigo mouro e a espelta, mas também a aveia, a cevada e o sorgo.

$\mathrm{O}$ testemunho da Eneida e o ritual da confarreatio permitem-nos vislumbrar um pouco a arqueologia do fabrico do pão. Este teria surgido pela constatação de que o potencial nutritivo dos cereais aumentava se fossem previamente esmagados, mesmo reduzidos a farinha, amassados com água e sujeitos a um processo prévio de cozedura. Destas primeiras fases, estaria arredada a fermentação como processo enzimático que favorece a digestibilidade e o sabor do pão. Os povos aderiram diferenciadamente à fermentação, mas sabe-se que, no Egipto, as vantagens deste procedimento eram conhecidas desde o quarto milénio a.C.

A arqueologia experimental e a observação dos hábitos culinários mais ancestrais dos povos da bacia mediterrânica mostram, contudo, que esta modalidade primitiva de produzir pão se mantém. As pizzas e a polenta italiana, os crepes franceses, os bolos de sertã dos Açores, o milho frito da Madeira, o pão pita do Médio-Oriente e o pão que se vende nos países da África Magrebina conservam este princípio que é a base da gastronomia mediterrânica: uma base de massa pouco fermentada feita de cereais em cozedura achatada, em fogo directo, em superfícies previamente aquecidas, frita ou mesmo no forno, é usada para suportar ou para envolver outro tipo de alimentos, salgados ou doces. Confortável e prático, diversificado do ponto de vista nutritivo, dispensa uso e lavagem de utensílios, enfim todas as vantagens que nós hoje reconhecemos sempre que compramos uma pizza em take-away.

Este passo da Eneida mostra representa a chegada à interpretação de um oráculo hermético, e mesmo recebido com cepticismo. Afinal, a resposta estava ao alcance de um gesto tirado do quotidiano, que passava por dispor os alimentos sobre uma base de cereais, afinal o que o homem do Mediterrâneo faz há milénios. Virgílio, com a sua mestria, associa a este gesto do quotidiano uma dimensão religiosa e política: cumpre-se um oráculo e, com este gesto, antecipa-se a fundação de uma cidade. O pão assume neste passo a dimensão universal que the conhecemos de fundamento de uma civilização urbanizada. 


\section{A que sabiam os doces romanos? O passum como adoçante}

Como é por demais conhecido, na Europa, o uso do açúcar de cana faz parte, como o milho, o cacau, a batata e o tomate, da aventura das descobertas do novo mundo na Época Moderna. Hoje vemos com dificuldade o nosso quotidiano sem estes produtos básicos, mas a verdade é que o homem europeu viveu milénios sem uma série de bens que hoje são primordiais, mas que estão entre nós há poucos séculos.

A alimentação é, provavelmente, uma das áreas da cultura humana que mais se adapta às novas circunstâncias, ao aparecimento de novos produtos e à escassez de outros. Mas, como um contínuo invisível, estas mudanças não permanecem na memória activa dos povos, talvez por estarem ligadas a uma realidade do quotidiano, muitas vezes remetidas para uma natureza instrumental.

Assim, as fontes para estudar as formas de alimentação dos romanos escassas vezes são directas ${ }^{3}$ : o livro De Re Coquinaria de Apício, escrito no séc. I d.C., constitui uma excepção. No entanto, apresentando uma lista variada de receitas culinárias, o seu carácter informativo sobre o padrão da alimentação do romano deve ser matizado por várias razões: em primeiro lugar, de acordo com os testemunhos de outros escritores seus contemporâneos, este pioneiro da gastronomia não personifica exactamente o modelo de um romano comum. Depois, porque da obra De Re Coquinaria só se conhece uma versão do séc. IV, ou seja, é possível que tenha sido atribuído a uma personalidade famosa do séc. I, conhecida pelo seu requinte e gosto culinário, uma recolha variada de receitas, com fontes diversas e em que se cruzam diferentes momentos históricos ${ }^{4}$.

Restam-nos os testemunhos indirectos: numerosos passos da literatura latina, particularmente da comédia, do romance e de epístolas apresentam lampejos do que seria a cozinha comum do romano. A arqueologia constitui uma fonte preciosa de informação: cenas prandiais em frescos, lojas de "takeaway" que animavam as principais urbes, permitem reconstituir sobretudo a inserção da realidade alimentar no quotidiano romano. Acrescem as informações, também indirectas, dos historiadores, alusivas ao comércio de

3 Servimo-nos, para este trabalho, do livro de Andrew Dalby, Food in the Ancient World from A to Z, London, Routledge, 2003, 408 pp.

4 Séneca, Consolatio ad Helviam, 10; Plínio o Antigo, Naturalis Historia 9, 66; 10, 133, e Tácito, Annales. 4,1,2 destacam nele o seu carácter excêntrico e refinado, a sua enorme riqueza, que empregava na organização de elaborados festins. 
bens alimentares. Neste âmbito, sem dúvida, os cereais ocupavam um lugar de destaque, pois o seu fluxo constante era uma preocupação para os governantes.

Como em qualquer sociedade avançada e complexa, a alimentação romana era variada. Determinados gostos poderão parecer estranhos ao homem actual, como, por exemplo, a mistura do doce e do salgado, ou o emprego do sabor doce em pratos tradicionalmente salgados, ou de carne ${ }^{5}$.

Como adoçantes, os romanos recorriam ao mel e aos preparados de frutos, quer como condimento ou tempero, quer como base principal. $\mathrm{O}$ processo de secagem dos frutos permitia a sua conservação e também a concentração natural dos seus açúcares (figos, uvas), e os frutos secos (nozes, amêndoas, pinhões) eram recurso abundante na cozinha romana. As tâmaras (palmulae ou dactyli) que nos habituamos hoje a identificar com a cozinha do Magreb, eram frequentes em Roma, dada a proximidade política e comercial com a margem sul do Mediterrâneo.

Mas a forma mais comum e acessível de adoçante era a que resultava da redução do mosto (sumo de uva) de modo a obter um xarope concentrado de uva. Concentrado e durável, o passum era um tipo de aproveitamento das uvas demasiado maduras ou de inferior qualidade. No meio rural, o fabrico de passum seria uma das muitas formas de transformar os proventos da terra, e julgamos que disso nos dá conta Virgílio na sua Geórgica I, 291-296, quando nos descreve o idílico cenário do interior de uma casa de agricultores romanos 6 :

"Et quidam seros hiberni ad luminis ignis
pervigilat ferroque faces inspicat acuto;
interea longum cantu solata laborem
arguto coniunx percurrit pectine telas,

5 A surpresa deve diminuir, contudo, se tivermos em conta que a cozinha antiga portuguesa preservava este princípio, como pode ser observado no Livro de Cozinha da Infanta D.Maria. Prólogo, Leitura, Notas aos textos, glossário e índices de Giacinto Manuppella, Lisboa, Imprensa Nacional, 1986. Ainda hoje subsistem como raridades culinárias entre nós, por exemplo, a farinheira doce, o feijão assado, ou mesmo o pudim de abade de Priscos, pratos que resultam do adoçar de uma base de carne.

6 Também nas Georg. II, 93-94, et passo psithia utilior tenuisque lageos/ temptatura pedes olim uincturaque linguam” e Georg. IV, 268-271, “...aut igni pingua multo/ defruta uel psithia passos de uite racemos". 
aut dulcis musti Volcano decoquit humorem

et foliis undam trepidi despumat aeni.

"E ele, nos serões de Inverno, à luz do fogo

Permanece vigilante, e com ferro aguçado talha os feixes.

Entretanto, aliviada do longo trabalho pelo canto,

A esposa atravessa a tela com pente veloz,

Ou com a graça de Vulcano ferve o líquido do doce mosto

E com folhas limpa a superfície espumosa do vinho".

O passum era um ingrediente básico para as receitas dos dulcia domestica de Apício ${ }^{7}$ e Virgílio fala, nas Geórgicas, do passum psythium, feito com uvas tidas por originárias da Grécia.

Os exemplos de receitas colhidas no livro de Apício mostram a utilização deste passum não como bebida, mas como ingrediente: integra a confecção de doces, como já apontámos, mas é também amplamente utilizado como tempero de pratos de carne, de peixe e de legumes. Surge generalizadamente associado ao uso do liquamen $^{8}$ e do acetum, e em alternativa com o mel, o que nos leva a pensar que seria o tempero de contraponto doce, em confronto com o vinagre e o liquamen, respectivamente acre e salgado ${ }^{9}$.

7 De Re Coquinaria, VII, 11 Dulcia domestica et melcae "doces caseiros e doces de leite" 1. Dulcia domestica: palmulas uel dactilos (tâmaras) excepto semine, nuce vel nucleis (nozes ou amêndoas) vel piper (pimenta) tritum infercies. sales foris contingis, frigis in melle cocto, et inferes 4. Dulcia piperata: mittis mel, merum, passum, rutam (arruda) eo mittis nucleos, nuces, alicam elixatam (espelta cozida). concisas nuces auellanas tostas adicies (avelãs picadas e torradas), et inferes; 5. Aliter dulcia: piper, nucleos, mel, rutam et passum teres, cum lacte [et] tracta coques. coagulum coque cum modicis ouis. perfusum melle (mel fundido), aspersum inferes.

8 O liquamen, termo que Apício utiliza para designar o garum, é um tempero obtido a partir da fermentação ao sol e da salga de peixes gordos.

9 De Re Coquinaria II, 2, 10 numa receita de cereais cozidos (apothermum), junta-se "caroenum uel passum". II, II, 9, numa receita de frango, usa-se "liquamen et passum". Em III, 2, 2, numa receita de pulmentarium (peras) usa-se liquamen et passum, 2, 6, num prato de abóboras, usa-se "mel uel passum, liquamen et acetum". $\mathrm{O}$ caroenum era um tipo de passum reduzido a um terço do seu volume. As receitas de pêra e de abóbora estão incluídas no capítulo dedicado aos cepuros, aos produtos hortículas. 
Não é fácil encontrar um equivalente actual e comercializado do passum: os vinhos licorosos e doces utilizam, em graus diferentes, a fermentação. Mosto concentrado e xarope de uva são contudo, numa perspectiva experimental da arqueologia, fáceis de obter em qualquer cozinha $^{10}$. Mas a cozinha macrobiótica utiliza o sumo de uva, em que este é fervido até reduzir o seu volume, pensamos que mais pelo reconhecimento das qualidades do produto, que permite dispensar o açúcar refinado, do que pelo antecedente latino. As versões mais concentradas permitem dispensar o frio, sem riscos de fermentação.

Acrescentamos uma nota final, relativa aos doces. A doçaria e os cereais são, da cozinha romana descrita em Apício, os que mais facilmente se adaptam ao gosto do homem contemporâneo. Assim, fazem parte da cultura gastronómica mediterrânica os frutos secos, as tâmaras e os frutos frescos secos ao sol (passas, figos), assim como as especiarias ou ervas de gosto mais activo (pimenta e arruda, para os romanos, nos nossos dias erva-doce e cravinho). O leite e os ovos são também de uso generalizado. Não deixa de ser curioso notar que é na nossa cozinha tradicional ou rural que encontramos a maior proximidade com estes sabores latinos: os torrões de frutos secos; o leite azedo, utilizado em doces alentejanos, os doces que resultam da pasta de amêndoa, parecem-nos não só próximos de equivalentes na cozinha magrebina ou na cozinha do Médio-Oriente, como herdeiros de processos muito semelhantes aos usados na cozinha romana.

PAULA BARATA DIAS

10 Fizemos a experiência e utilizámos o produto obtido na confecção de sobremesas (tal como qualquer compota ou xarope de frutas) e também como bebida, diluído em água. 